\title{
Interactions of Metabolic Hormones, Adipose Tissue and Exercise
}

\author{
Robert G. McMurray and Anthony C. Hackney \\ University of North Carolina at Chapel Hill, Chapel Hill, North Carolina, USA
}

\section{Contents}

Abstract.................................................................... 393

1. Hormonal Regulation of Lipid Metabolism . . . . . . . . . . . . . . . . . . . . . . . . . . . . . . . . . . . . . . . 395

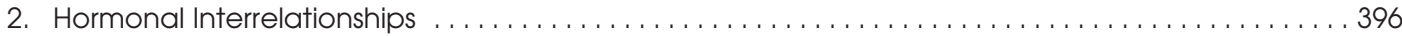

3. Obesity-Induced Modifications of Hormonal Interactions . . . . . . . . . . . . . . . . . . . . . . . . . . . . . 399

4. Energy Restriction and Metabolic Hormones ......................................... 401

5. Exercise-Induced Changes in Lipid Metabolism . . . . . . . . . . . . . . . . . . . . . . . . . . . . . . . 402

6. Exercise-Induced Changes in Adiposity . . . . . . . . . . . . . . . . . . . . . . . . . . . . . . . . . . . . . . . . 403

7. Exercise-Induced Modifications of Hormones . . . . . . . . . . . . . . . . . . . . . . . . . . . . . . . . . . 403

7.1 Acute Exercise: Normal Weight Individuals. . . . . . . . . . . . . . . . . . . . . . . . . . . . . . . . . . . . . 403

7.2 Acute Exercise: Obese Individuals . . . . . . . . . . . . . . . . . . . . . . . . . . . . . . . 404

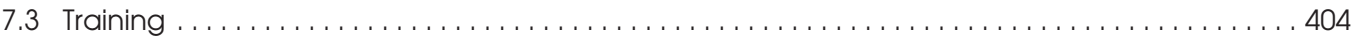

8. Relationship Between Exercise-Induced Hormonal Changes and Body Fat . . . . . . . . . . . . . . . 406

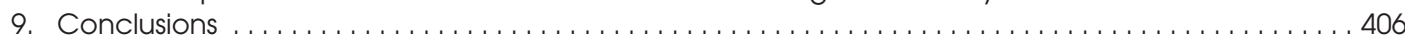

\section{Abstract}

Physiological and psychological systems work together to determine energy intake and output, and thus maintain adipose tissue. In addition, adipose tissue secretes leptin and cytokines, which induces satiety and has been linked to catecholamines, cortisol, insulin, human growth hormone, thyroid hormones, gonadotropin and lipolysis. Thus, adipose tissue is acted upon by a number of physiological stimuli, including hormones, and simultaneously, is an active component in the regulation of its own lipid content. All of the hormones mentioned above are associated with each other and respond to exercise and exercise training. Thus, exercise is one of the major links between the hormonal modulators of energy intake and output. It appears that the sympathetic nervous system and the catecholamines are key components facilitating the lipolytic activity during exercise. These two neuroendocrine factors directly affect adipose metabolism and metabolic hormones that influence adipose metabolism. Acute low- and moderate-intensity exercise causes hormonal changes that facilitate lipolytic activity. Exercise training reduces these hormonal responses, but the sensitivity to these hormones increases so that lipolysis may be facilitated. Large amounts of adipose tissue blunt the metabolic hormonal responses to exercise, but the sensitivity of these hormones is increased; thus maintaining normal lipolytic activity. Although the physiological role of the endocrine system during exercise 
and training is significant, other training effects may have as great, or greater influence on lipolytic activity in adipose tissue.

Adipose tissue is maintained by a complex interaction of a number of physiological and psychological systems that regulate energy intake and energy output (figure 1). Typically, energy intake is controlled by hunger, appetite and satiety. ${ }^{[1]}$ Hunger and satiety appear to be genetic or physiological in nature, receiving input from blood glucose, splanchnic neurons, endogenous opiates, neurotransmitters, the gastrointestinal system and leptin. ${ }^{[2]}$ Conversely, appetite appears to be psychological or cultural, and is a learned response to foods. Energy output is related to metabolic rate, which, at rest, is controlled by various hormones and genetic factors. Physical activity (e.g. exercise) increases energy output directly, but also affects a number of hormones that control metabolic rate and hunger. Thus, exercise appears to be the one perturbation that has the potential to influence both sides of the energy balance equation (i.e. energy intake and energy output).

Adipose tissue is not passive, as it influences metabolic activity in other tissues including muscle and liver. ${ }^{[3]}$ Adipose tissue secretes the hormone leptin, which has a controlling effect on satiety and hunger. In animals, leptin has also been shown to influence spontaneous activity levels and increase energy expenditure. ${ }^{[4,5]}$ In humans, studies on the effects of leptin on spontaneous activity levels are

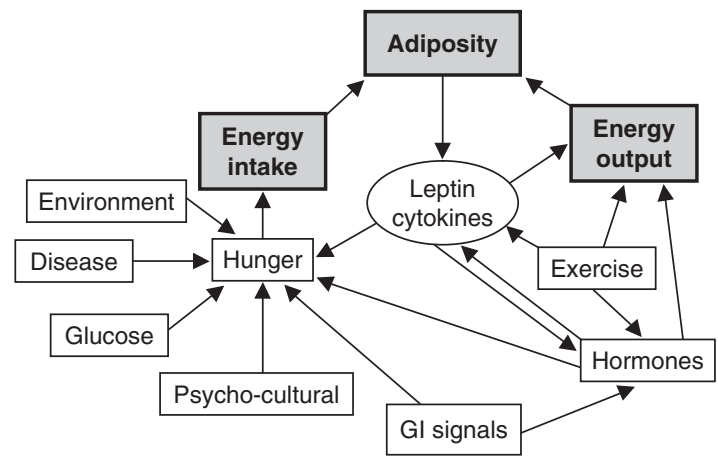

Fig. 1. General schematic of the factors that influence energy intake, energy output and their relationship to adiposity. GI = gastrointestinal. not as convincing. ${ }^{[6,7]}$ Leptin has been linked to several other hormones ${ }^{[3,8,9]}$ that have direct effects on carbohydrate and lipid metabolism. In addition, adipose tissue releases a number of cytokines (e.g. adiponectin, interleukin [IL]-6, tumour necrosis factor- $\alpha[\mathrm{TNF} \alpha]$, resistin) that can influence insulin, ${ }^{[10,11]}$ stimulate corticotropin-releasing hormone $(\mathrm{CRH})^{[12]}$ and ultimately cortisol, ${ }^{[13]}$ which in turn increases lipolysis. ${ }^{[11,14]}$ Leptin may also be affected by exercise. ${ }^{[15,16]}$ Thus, adipose tissue is an active component in the regulation of the body's overall fat content.

From an endocrine perspective, a number of hormones regulate lipid metabolism including, catecholamines, corticosteroids, human growth hormone (hGH), thyroid hormones and gonadotropins (androgens and estrogens). All of these hormones can, therefore, have an influence on adipose tissue and all of these hormones have been in some way related to, or associated with, leptin. ${ }^{[3,9]}$ In addition, these hormones appear responsive to exercise and exercise training. ${ }^{[17]}$ Thus, exercise is one of the major links between the hormonal modulators of energy intake and output. This article will attempt to explore the relationship between these hormones and adipose tissue with emphasis on how exercise influences this relationship.

A vast body of literature has shown relationships between androgens, catecholamines, cortisol, hGH, insulin and thyroid hormones. Most of this information has come from studies of isolated cell, animal, disease states, drugs and correlation studies in humans. In addition, the relationship between these hormones at rest, during stress and exercise is influenced by the sex of the individual. ${ }^{[17]}$ These sex-related effects in turn, influence energy substrate metabolism. The role of sex is a treatise beyond the scope of this article. This topic is addressed in a recent article by Braun and Horton. ${ }^{[18]}$ Finally, many other factors besides exercise influence these hormones, such as circadian rhythm, thermoregula- 
tion or dietary composition, but a full discussion of these factors is beyond the scope of this review.

\section{Hormonal Regulation of Lipid Metabolism}

In order to understand the influence of exercise on the interaction of the endocrine system and body fat, a brief précis of the interaction of the metabolic hormones and lipid metabolism is needed. Much further in-depth discussions of this can be found in Tremblay et al., ${ }^{[19]}$ Goldberg and Elliott, ${ }^{[20]}$ Brouns and van der Vusse, ${ }^{[21]}$ and three companion articles by Jeukendrup and colleagues. ${ }^{[22-24]}$ The primary hormones involved with lipid metabolism are the catecholamines, cortisol, hGH and thyroid hormones; however, other hormones, including glucagon, insulin, androgens and estrogens, can be involved in specific situations. Of this list of hormones, the catecholamines, epinephrine (adrenaline) and norepinephrine (noradrenaline), appear to be the most important. The hypothalamus of the brain appears to centrally integrate the various metabolic, nervous, hormonal signals and interacts with the anterior pituitary to determine functional status of many of these hormones. ${ }^{[25]}$

Stressful events (physiological or psychological) cause activation of the sympathetic nervous system (SNS) and the release of the catecholamines. The catecholamines influence both food intake and metabolic rate. The catecholamines suppress food intake via an effect on the appetite centre within the hypothalamus, reducing the sensation of hunger. Regarding metabolism, initially the SNS responds, releasing mostly norepinephrine. The SNS has been shown to innervate adipose tissue, causing lipolysis and the release of glycerol and free fatty acids into the circulation. ${ }^{[26,27]}$ In addition, high levels of activity in the SNS inhibit food intake and food absorption. ${ }^{[28]}$ If the stress is perceived as significant, the adrenal glands are activated and release mainly epinephrine, further increasing adipocyte lipolysis via activation of hormone-sensitive lipase. The effects of these adrenergic hormones are dependent upon the type of receptor ( $\alpha$ - or $\beta$-receptor) at the target tissue. Subcutaneous adipose tissue appears to con- tain a majority of $\alpha_{2}$-receptors that when activated, have the propensity to inhibit lipolysis; whereas intra-abdominal adipose contains more $\beta$-receptors that, when activated, increases lipolysis. ${ }^{[28]}$ Thus, this activation of the catecholamines has the tendency to reduce abdominal fat while sustaining subcutaneous fat. ${ }^{[29]}$ The effect of the catecholamines on lipolysis is most apparent during exposure to stress. In a normal sedentary state, the catecholamines appear to account for only $2-3 \%$ of 24 -hour energy expenditure. ${ }^{[28]}$

Insulin exerts an influence on lipolysis. Insulin increases adipocyte lipoprotein lipase activity, thus promoting fat storage particularly in the subcutaneous tissues. ${ }^{[30]}$ Insulin enhances the incorporation of glucose into the triglyceride molecule, mostly as the glycerol portion. Concomitantly, insulin inhibits lipolysis by inhibiting the effects of hormone-sensitive lipase, cyclic adenosine monophosphate and protein kinase $\mathrm{A}$.

$\alpha$-Adrenergic receptors are also located in the $\beta$ cells of the pancreas and, when stimulated, suppress insulin secretion. Conversely, $\beta$-adrenergic receptors are more prevalent in the $\alpha$-cells of the pancreas and when activated release glucagon. The inhibition of insulin and the secretion of glucagon work in concert to increase adipose tissue lipolysis. In healthy individuals, this effect is only mediated during stressful events, such as thermal stress, hypoglycaemia or exercise.

The thyroid hormones, in particular triiodothyronine $\left(\mathrm{T}_{3}\right)$ can stimulate metabolic rate and increased adipose tissue lipolysis, potentially via an interaction with the catecholamines. The combined effects of thyroid hormones and catecholamines enhance mobilisation of triglycerides from adipose tissue and increase fatty acid lipogenesis in the liver. ${ }^{[31]}$ Yamaki et al. ${ }^{[32]}$ have suggested that increased $\mathrm{T}_{3}$ exposure causes an augmentation in mitochondrial density, which elevates resting metabolic rate. Thus, with consumption of an isocaloric intake, elevated $\mathrm{T}_{3}$ results in weight loss, while decreased $\mathrm{T}_{3}$ levels results in weight gain. ${ }^{[33]}$ Conversely, weight loss causes circulating $\mathrm{T}_{3}$ to decline. ${ }^{[34]}$ The thyroid hormones are controlled by the 
hypothalamus (thyrotropin-releasing hormone [TRH]) and the pituitary (thyroid-stimulating hormone $[\mathrm{TSH}])$. TSH has been shown to activate hormone-sensitive lipase and increase lipolysis, but this effect appears weak. ${ }^{[30]}$ In general, these hormones respond slowly and their involvement is thought of as a more long-term control mechanism.

In a resting state, both the glucocorticoids (cortisol) and hGH have roles in regulating lipid metabolism. ${ }^{[35-37]}$ A recent microdialysis study using men has shown that glucocorticoids and hGH can increase systemic and regional lipolysis. ${ }^{[38]}$ Infusion of hydrocortisone succinate elevated palmitate (a marker of systemic lipolysis) approximately $70 \%$ and lowered interstitial glycerol flux (an index of regional lipolysis) by approximately $50 \%$. The infusion of hGH increased systemic lipolysis and glycerol flux similarly to the cortisone infusion. ${ }^{[38]}$ When both hormones were infused the effects were greater, but not additive, suggesting some synergistic activity. Studies on post-surgery ${ }^{[37]}$ or obese ${ }^{[33]}$ patients also provide support for a lipolytic effect of cortisol. In contrast, studies on exogenous hGH administration in normal individuals do not completely support the lipolytic effect of hGH. ${ }^{[34,39,40]}$

Sex-steroid hormones also have lipolytic activity. Estradiol and estrogens have been shown to increase lipolytic activity in women. ${ }^{[41-43]}$ The actions appear to be mediated by: (i) estradiol reducing insulinbinding capacity; ${ }^{[41]}$ (ii) a direct effect of estradiol on liver lipolytic enzymes, namely acetyl coenzyme-A carboxylase and fatty acid synthetase; ${ }^{[42]}$ or (iii) possibly by reducing glucose uptake in muscle. ${ }^{[44]}$ Androgens may also have a minor influence on lipid metabolism at rest. ${ }^{[36,45]}$ This effect has been inferred from studies that administered testosterone to overweight individuals and found decreases in visceral fat without loss of lean body mass. ${ }^{[46,47]}$ The mechanism of this response is presently unknown but some researchers have suggested that testosterone may directly influence enzymes of adipose metabolism, ${ }^{[45,48]}$ while Seidell and colleagues ${ }^{[49]}$ suggest that testosterone may impart its lipolytic effects indirectly on sex-hormone binding globulin, which in turn, affects insulin.

\section{Hormonal Interrelationships}

Figure 2 is a model representing the interrelationships of the major metabolic hormones that influence energy intake. The relationships are very complex with some pathways enhancing the activity of other hormones and others having an inhibitory influence. Still, other relationships have been proposed, but not proven to exist. In addition, many of the hormones have central nervous system receptors that have differing effects from the somatic system, further complicating the understanding of these relationships. To simplify the complexity of these relationships, this article will examine each of these hormonal relationships independently; presenting the information on the pathways with what knowledge is presently known.

The relationship between the catecholamines and various hormones has been extensively studied. $\beta$ Adrenergic receptor blockage with propranolol, which reduces the influence of catecholamines, appears to enhance the hGH response to growth hormone-releasing hormone (GHRH) or hypoglycaemia. ${ }^{[50]}$ Relationships appear to exist between the catecholamines and thyroid hormones, pancreatic hormones and possibly glucocorticoids, as mentioned above. Also, there is also some suggestion that elevated insulin levels cause SNS stimula-

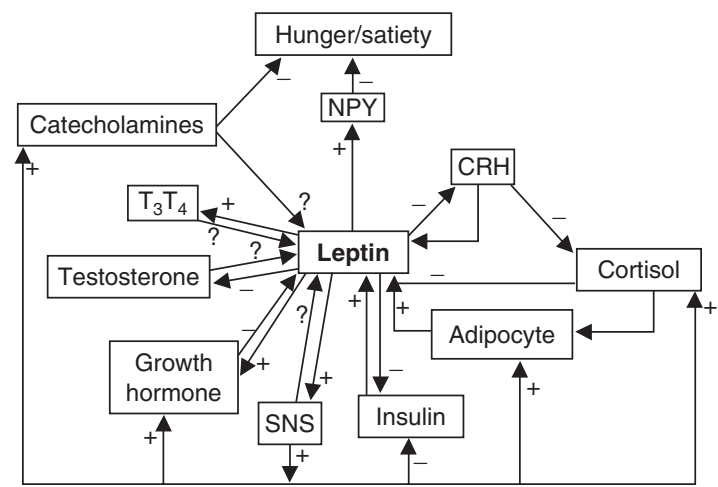

Fig. 2. The interrelationship between metabolic hormones, leptin and hunger. $\mathbf{C R H}=$ corticotropin-releasing hormone; NPY = neuropeptide-Y; SNS = sympathetic nervous system; $\mathbf{T}_{3}=$ thyroxine; $\mathbf{T}_{4}=$ tri-iodothyronine; - indicates pathway inhibits the activity of other hormones; + indicates pathway enhances the activity of other hormones; ? indicates relationship has been proposed, but is not proven to exist. 
tion. ${ }^{[51]}$ Presently, this relationship is not well understood and the causes and purpose(s) are in need of investigation.

At rest, cortisol is negatively associated with hGH. ${ }^{[52-54]}$ This effect may be mediated centrally, as Rosmond et al. ${ }^{[55]}$ has shown that abdominal obesity is related to weak glucocorticoid receptor reactivity in the hippocampus, which ultimately modifies the hypothalamic-pituitary-adrenal axis (HPA) responses. Thus, GHRH is suppressed, ${ }^{[52,53]}$ resulting in a reduction of hGH. This effect may be genetic. ${ }^{[5]}$ The cause/effect relationship between these two hormones is still equivocal, as Hermida et al. ${ }^{[56]}$ have shown that in short-stature boys, a normal circadian rhythm for cortisol exists despite the abnormal hGH pulse amplitude. Ghizzoni et al. ${ }^{[57]}$ using time-course studies, has suggested that any interactions between cortisol and $\mathrm{hGH}$ is mediated by leptin. As mentioned earlier, cortisol and hGH may be correlated, but their effects on lipolysis are not totally additive when co-administered. ${ }^{[38]}$ With respect to the influence of cortisol on other metabolic hormones, a relationship between cortisol and insulin may exist as cortisol may induce insulin resistance. ${ }^{[26]}$ In addition, cortisol is also negatively associated with testosterone ${ }^{[58]}$ and estrogens. ${ }^{[59]}$

Connections also exist between the sex hormones and other metabolic hormones. Studies have proposed that a high level of free testosterone increases insulin sensitivity. ${ }^{[60,61]}$ In support, obese individuals generally have decreased circulating testosterone levels with concomitant decreased insulin sensitivity ${ }^{[26]}$ and the administration of testosterone appears to alleviate the insulin resistance. ${ }^{[49]}$ Although evidence supports a relationship between androgens and estrogens and other metabolic hormones, there appears to be no relationship between androgens and hGH. Ovesen et al. ${ }^{[62]}$ administered exogenous hGH for 14 days to healthy men and found no increases in testosterone. Hackney and Ness ${ }^{[63]}$ found that 8 weeks of intensive exercise training elevated hGH, while testosterone was suppressed.

With regard to estrogens, Hansen and Weeke ${ }^{[64]}$ have shown that fasting hGH levels were related to estradiol, but not all studies agree. ${ }^{[65]}$ Estrogens have been negatively associated with insulin ${ }^{[41,42,64]}$ Whether this relationship is due to a direct effect of estrogen on pancreatic $\beta$ cells or a decrease of insulin receptor activity to a given insulin level is still debatable. Ding et al. ${ }^{[59]}$ have suggested that elevated cortisol may disrupt the hypothalamic-pituitary-gonadal axis resulting in decreased estrogen levels. Whether this relationship is because of a stress response or insufficient energy intake is also debatable. ${ }^{[66]}$ Estradiol appears to be related to leptin. ${ }^{[67]}$ Leptin could be the signal that informs the reproductive system about the energy status; thus, permitting or blocking reproduction and menses in women. ${ }^{[68]}$ Once again, it is not known if this effect of leptin is directed to the ovaries or mediated through the hypothalamic-pituitary-gonadal axis.

The thyroid hormones also interact with hGH. Giustina and Wehrenberg ${ }^{[69]}$ summarised information from eu-, hyper- and hypothyroid patients. Hyperthyroid men with elevations of $\mathrm{T}_{3}$ and thyroxine ( $\left.\mathrm{T}_{4}\right)$ seem to have elevated somatostatin, which suppresses GHRH and consequently hGH. Conversely, depressed thyroid function (hypothyroidism) also appears to suppress nocturnal hGH secretion by decreasing hGH production in the pituitary. Harvey ${ }^{[70]}$ noted that hypothalamic TRH may actually be a releasing hormone for $\mathrm{hGH}$, which has resulted in TRH being used as a clinical test for hGH insufficiency. ${ }^{[71]}$ In addition, hGH also appears to have an influence on thyroid hormones, as the administration of hGH stimulates the conversion of $\mathrm{T}_{4}$ to the active state $\mathrm{T}_{3}$ and a concomitant increase in energy expenditure. ${ }^{[72]}$ Thus, a possible link between the thyroid hormones and hGH; however, not all studies agree with this relationship. Coiro et al. ${ }^{[73]}$ studied this relationship in obese and non-obese men using the TRH challenge test. They found that men with normal, basal TSH levels did not increase hGH levels in response to the TRH challenge; whereas, individuals with elevated basal TSH levels responded to the TRH with a release of hGH. Thus, the relationship between thyroid hormones and $\mathrm{hGH}$ is not clear.

Leptin appears to have a role in both energy intake and energy expenditure (see figure 1). When 
energy intake is restricted, leptin decreases, causing energy conservation and decreased thermogenesis. Conversely, leptin increases as body fat increases in an attempt to reduce food intake and increase thermogenesis. ${ }^{[74]}$ Leptin's action on hunger/food intake appears to be regulated through its effect on hypothalamic neuropeptide-Y (NPY). ${ }^{[74]}$ With regard to energy expenditure, leptin appears to activate the SNS and ultimately thermogenesis; possibly through galin-like peptide, as Hansen et al. ${ }^{[75]}$ have shown that in mice the central administration of galin-like peptide decreased body mass and increased core temperature. Conversely, activation of the SNS decreases leptin production in white adipose tissue, while sympathetic blockade increases circulating leptin. Thus, there appears to be a reciprocal relationship between leptin derived from the white adipocytes and the SNS. ${ }^{[76]}$ This relationship has been shown in sub-human species and needs to be verified in humans. ${ }^{[76]}$

Leptin may also be related to other metabolic hormones. Simsch et al. ${ }^{[77]}$ have shown that in humans, low leptin causes a reduction in all the hypothalamic-releasing hormones (thyroid, gonadal and hGH), except adrenocorticotropic hormone (ACTH). Florkowski et al. ${ }^{[78]}$ administered hGH to overweight adults, which lowered body fat and reduced leptin. Also in support, Tuominen et al. ${ }^{[79]}$ found an inverse relationship between $\mathrm{hGH}$ and leptin. Ghizzoni and colleagues, ${ }^{[57]}$ using time course analyses in prepubertal children, found a sexspecific 2-5 hour lag between hGH and leptin. They suggested that the lag appears appropriate since hGH affects leptin gene expression. Intriguingly, Ghizzoni and colleagues did not eliminate the possibility that the relationship may be more mathematical than physiological. Studies in adults have shown positive statistical associations between leptin and thyroid hormones. ${ }^{[15,80-82]}$ A study on fasting animals found that decreased leptin caused increased production of NPY, which resulted in decreased thyroid hormone production. ${ }^{[83]}$ In contrast, Alagna et al. ${ }^{[84]}$ reported that leptin immediately declined with fat loss in 38 morbidly obese post-bariatric surgery patients, but $\mathrm{TSH}$ and free $\mathrm{T}_{4}$ were un- changed. Thus, the effects of thyroid function and leptin may be associative rather than causal, although this point remains to be determined.

Convincing evidence from animal studies has shown a physiological feedback loop between leptin and HPA; thus, ultimately cortisol. Ahima et al. ${ }^{[74]}$ administered leptin to ob/ob mice and found an inhibition of CRH. Also, the administration of synthetic glucocorticoids to mice elevated leptin production, ${ }^{[85]}$ due to a presently unknown mechanism that reduces messenger RNA (mRNA) for $\mathrm{CRH}$ receptors. ${ }^{[86]}$ In contrast to the animal and isolated cell studies, human studies on the relationship between resting (non-stressful situations) leptin and cortisol concentrations are equivocal at best. ${ }^{[87,88]}$ However, some research on human adults suggests that leptin inhibits cortisol production; ${ }^{[89-91]}$ while others indicate increases in cortisol acutely stimulate leptin secretion in adipocytes. ${ }^{[92]}$ These relationships in humans appear time-dependent, as an elevation of cortisol typically occurs hours before a leptin response. ${ }^{[57]}$

There appears to be a moderate relationship between leptin and sex steroid hormones. Paolisso et al., ${ }^{[67]}$ using 80 healthy men and women, have shown moderate association between leptin and testosterone or estradiol, independent of body fat or insulin. They speculated that leptin could modulate gonadal activity by informing the reproductive HPA about nutritional status. More recent evidence suggests that testosterone suppresses leptin mRNA; thus, implying a direct link between changes in testosterone and leptin production. ${ }^{[93]}$ The relationship between leptin and estrogens may actually be moderated by cortisol ${ }^{[58]}$ however, more research is needed in humans to substantiate this hypothesis.

A reciprocal relationship may exist between leptin and insulin. ${ }^{[94]}$ Tanizawa et al. ${ }^{[95]}$ have noted that leptin acts directly on the pancreatic $\beta$ cells stimulating insulin secretion at rest. In vitro human studies, as well as animal studies, have also noted that insulin-mediated increased cellular glucose uptake stimulates leptin expression and secretion. ${ }^{[96,97]}$ These studies on insulin, combined with the other studies on leptin and metabolic hormones, suggest that lep- 
tin may be the central focal point (figures 1 and 2) and that energy balance may be the product of the interactions between leptin and these metabolic hormones. ${ }^{[98-100]}$ However, a growing body of evidence also suggests that the SNS or catecholamines may be equally as important. ${ }^{[29,57]}$ As a note of caution with regard to accepting the interpretation of these results, the majority of studies presented above derived their conclusions from correlations, which show associations but not direct cause or effect. Thus, further confirmatory research is needed.

Since all of these hormones appear to interact with each other, the question remains as to how these hormones interact to influence overall lipid metabolism at rest. Substrate use is generally controlled by substrate availability and is related to blood glucose status. If glucose is in abundance (e.g. post-prandial), insulin elevates, activating adipose lipoprotein lipase, which encourages the storage of fats and a reduction in $\beta$-oxidation or the use of lipids for energy. Increased lipid storage increases leptin, reducing hunger and theoretically, food intake. Leptin may also inhibit cortisol allowing for greater glucose uptake and metabolism. Furthermore, the increased leptin could influence $\mathrm{T}_{3}$ to maintain resting metabolic rate.

When glucose levels are low, as occurs after an overnight fast, adipocyte lipolysis is increased. The hypothalamus activates the SNS and adrenal glands so that the catecholamines tend to elevate, resulting in suppressed insulin and enhanced glucagon to increase gluconeogenesis. The presence of the catecholamines increases hormone sensitive lipase and also increases adipocyte sensitivity to $\mathrm{T}_{3}$. This combination enhances lipolysis and fatty acid oxidation. The catecholamines and SNS subsequently stimulate the hypothalamus to release $\mathrm{CRH}$, resulting in a rise in ACTH and ultimately cortisol, which improves glucose conservation and lipid use for energy. Although in a resting, fed state the lipolytic effect of cortisol may be small, if the fasting becomes chronic, then the inhibition of leptin on ACTH is attenuated and cortisol-induced lipolysis is enhanced and peripheral cellular glucose uptake is reduced. Although the decline in leptin may inhibit
$\mathrm{GHRH}$, and therefore $\mathrm{hGH}$, the influence of the catecholamines on the GHRH appears stronger, and hGH output increases. ${ }^{[101,102]}$ The combined effect of hGH and catecholamines further increases lipolysis. Concomitantly, fasting causes circulating $\mathrm{T}_{3}$ to decline, which lowers resting metabolic rate. Thyroid hormones are controlled by TRH from the hypothalamus, which is influenced by the SNS and circulating catecholamines. In addition, the lower leptin could interact with TRH or TSH production and thus $\mathrm{T}_{3}$ to reduce resting metabolic rate. Therefore, the SNS and leptin appear to be central to the control of substrate utilisation.

\section{Obesity-Induced Modifications of Hormonal Interactions}

Large amounts of adipose tissue can modify hormonal profiles and the relationships between these hormones. Obesity has been shown to cause 'resistance' or loss of sensitivity (loss of response per unit of hormone) for several hormones. Obese individuals appear to have higher levels of SNS activity: ${ }^{[51,103]}$ however, the metabolic response to SNS stimulation appears reduced in obese individuals. ${ }^{[104]}$ This suggests that in obesity any compensatory effect of the SNS on metabolism to increase energy expenditure may not occur, making weight loss more difficult. ${ }^{[79]}$ In contrast to the SNS activity, circulating epinephrine levels in the obese can be either normal or reduced and the epinephrine response to stress (e.g. hypoglycaemia, exercise) is typically blunted. ${ }^{[105]}$ Del $\mathrm{Rio}^{[105]}$ has suggested that the blunted amine response to stress could be related to the exaggerated cortisol response that occurs in obese individuals, since glucocorticoids inhibit catecholamine production. Finally, the lipolytic action of catecholamines on visceral adipose is blunted. ${ }^{[28,29]}$ This blunted effect is probably related to the elevated leptin production associated with obesity, ${ }^{[78]}$ as increased leptin has been shown to be related to a down-regulation of the $\beta$-adrenergic receptor in white adipose tissue, resulting in a decreased responsiveness to sympathetic stimulation. ${ }^{[76]}$ 
Resting insulin ${ }^{[61,106]}$ and leptin ${ }^{[78]}$ levels are generally higher in obese individuals. Monroe et al. ${ }^{[107]}$ have shown that there is an association between these two hormones and sympathetic nerve activity and that leptin can act perhaps as a 'signal' to the sympathetic response. This suggests that the increase in leptin associated with obesity is necessary for the insulin response to occur. However, this time course has not been investigated. Although these two hormone levels are higher than normal, there appears to be a loss of systemic sensitivity to their presence in many obese individuals.

Obesity seems to enhance cortisol production and clearance in most studies; however, not all studies report this finding. ${ }^{[26]}$ Specifically, any stress, psychological and physiological, appears to elevate cortisol in individuals with central obesity more than in normal weight individuals. ${ }^{[26]}$ This could possibly be related to the increased SNS tone previously mentioned. ${ }^{[108]}$ Resting thyroid hormones appear to be within normal limits for obese individuals, provided no comorbidities exist. ${ }^{[73]}$ Total and free testosterone, free estrogen and sex hormone binding globulin levels are usually lower in obese individuals, but could also be normal. ${ }^{[33,60,109,110]}$ Low testosterone appears to decrease the lipolytic response to catecholamines; however, it may also decrease lipid uptake in the adipocyte. ${ }^{[93]}$ In addition, Jockenhoval et al. ${ }^{[111]}$ have suggested that low androgens permit leptin to increase, while testosterone treatment in hypogonadal men lowered leptin. Thus, the low testosterone would increase leptin, which could influence energy intake. Any reduction in circulating sex steroids appears to be related to lower luteinising hormone pulsitility, but since some obese women have normal menstrual function, further study is needed to elucidate the hormonal interactions. ${ }^{[112]}$

The interactions of these hormones seen in normal weight people are still apparent in obese individuals; however, the interactions are somewhat modified and we do not know which are the precedents or antecedents. Clearly, there must be some signal external of adipose tissue that initiates weight gain. Genetic factors are most likely initially involved, ${ }^{[26,113]}$ although environmental factors such as chronic stress may play a role. ${ }^{[114]}$ Possibly genetic factors may alter the SNS, ${ }^{[28,115]} \mathrm{HPA}^{[26]}$ and leptin receptors. The SNS has a role in both energy intake and energy expenditure. The literature suggests that SNS tone is often increased by obesity. ${ }^{[51,76,103]}$ The increased SNS tone has been linked to the hypertension associated with obesity. However, the metabolic response to SNS stimulation in these individuals appears to be blunted. ${ }^{[104]}$ The disregulation of SNS activity could be conceptualised as the antecedent to the hormonal responses. SNS also influences insulin; thus, diminished responsiveness to SNS stimulation, as seen in obesity, would allow insulin to increase encouraging fat storage and increased adiposity. ${ }^{[115,116]}$ Conversely, elevated insulin levels may cause SNS stimulation. ${ }^{[51]}$ Although this effect in overweight subjects has been related to renal and circulatory systems, an increased adrenergic effect on muscle may serve as a compensatory mechanism to increase energy expenditure, while a similar effect on adipose tissue may increase circulating fatty acids. ${ }^{[103]}$ These combined effects could help the body maintain weight homeostasis. ${ }^{[105]}$ However, the metabolic adrenergic effects are mediated mostly by the adrenal glands and their function may be suppressed by obesity. ${ }^{[105]}$ Thus, this hypothesis needs further verification in humans.

As previously noted, obese individuals typically have elevated insulin levels and can develop frank diabetes mellitus. ${ }^{[61,106]}$ The reason for the increased insulin secretion associated with obesity and the relationship between obesity and diabetes is not clear. Unger ${ }^{[117]}$ has speculated that initially, increased deposition of fat in pancreatic $\beta$ cells increases $\beta$-cell proliferation and a secondary increase of insulin secretion (the pre-diabetic state). As the obesity progresses, the lipid content increases and $\beta$ cell degeneration occurs reducing insulin production. Although not the major focus of the discussion, this hypothesis, which is based on animal research, is intriguing, as it suggests that the infiltration of fat into non-adipose tissue can have an impact on the homeostasis of other cells. Leptin may up-regulate IL-6 and TNF $\alpha$, both of which have a negative 
impact on the insulin-signalling pathway within the cell (particularly muscle). Thus, obesity not only influences the pancreatic cell insulin output, but the cellular insulin response, leading to hyperglycaemia.

As adipose tissue develops it releases leptin and cytokines (e.g. IL-1, IL-6, TNF $\alpha$, adiponectin, resistin) into the blood. IL-1 plays a role in lipid metabolism by directly increasing adipocyte lipase activity, and indirectly by lowering insulin ${ }^{[118]}$ and increasing cortisol. ${ }^{[13]}$ Cytokines are powerful stimulants of the HPA and through this cascade cause the release of cortisol; however, the cytokines may also exert their effects directly on the adrenal glands to release cortisol. ${ }^{[26]}$ The increased cortisol level, as well as the cytokines, in some way contribute to insulin resistance. ${ }^{[115]}$ Elevated cortisol and leptin may reduce GHRH and therefore hGH secretion, eliminating the normal lipolytic and calorigenic effect of hGH. In addition, elevated cortisol and leptin could indirectly reduce estrogens; thus, increasing lipoprotein lipase activity and decreasing lipolytic activity. ${ }^{[60]}$ Adipose tissue contains metabolic pathways for sex steroids. Accumulating large amounts of adipose may enhance the conversion of androgens to estrogen (testosterone aromatisation process), which would contribute to adipose deposition. ${ }^{[48,119]}$ Although these hormonal relationships appear logical and potentially could contribute to obesity, they are mostly theoretical at this time and are in need of future research.

\section{Energy Restriction and Metabolic Hormones}

Negative energy balance results in a significant change in the hormone milieu. In general, most circulating metabolic and anabolic hormone levels decline with energy restriction. The literature consistently shows that weight loss reduces insulin levels. ${ }^{[120-122]}$ Several mechanisms previously mentioned could account for this reduction: (i) reduction of fat infiltration into the islet of the pancreas; (ii) a reduction in SNS activity that would elevate leptin and, therefore, lower insulin; or (iii) the loss of fat resulting in less cytokine release and improved cellular glucoregulation requiring less insulin. Presently, these mechanisms are speculation and in need of verification. Most importantly, the reduction of insulin is a positive response, as insulin sensitivity (glucose uptake/unit of insulin) increases ${ }^{[121,122]}$ and the risk of diabetes may be reduced. ${ }^{[123,124]}$ The improvement in sensitivity, however, will not cause the conversion of frank diabetes to a normal glycaemic state. ${ }^{[125]}$

Studies on hypocaloric diets and thyroid hormone are also consistent, showing a decline in $\mathrm{T}_{3}$ or $\mathrm{T}_{4},{ }^{[126,127]}$ with a concomitant decline in basal metabolic rate. Similarly, significant weight loss reduces norepinephrine ${ }^{[128,129]}$ and leptin levels. ${ }^{[130-132]}$ Conversely, energy restriction increases hGH. ${ }^{[101,102,133,134]}$ Cortisol may be reduced by dietary-induced weight loss. ${ }^{[135-137]}$ Ironically, the ACTH response to $\mathrm{CRH}$ appears to be intact and free cortisol remains normal; thus, any reduction in cortisol may be related to a decrease in cortisol binding globulin. ${ }^{[137]}$ Kraemer et al. ${ }^{[135]}$ have also noted that if exercise is added to the weight-loss regimen, circulating cortisol may increase, or possibly remain unchanged.

Most studies support a reduction in circulating testosterone during energy restriction. ${ }^{[126,136,138,139]}$ However, not all studies agree, as Kraemer et al. ${ }^{[135]}$ found that 12 weeks of weight loss via dieting, resulting in $\sim 9 \mathrm{~kg}$ loss, caused no significant change in testosterone. Dieting may also reduce estrogens, but the reduction does not appear to disrupt normal ovulation $^{[140]}$ unless the energy restriction becomes severe. ${ }^{[141]}$ Any decrease in sex steroid hormones appears to be related to an altered luteinising hormone pulsitility. ${ }^{[66,140]}$ Thus, all the metabolic hormones are modified with energy restriction. However, it appears that once weight is stabilised and the diet becomes isocaloric, the hormonal milieu returns to normal.

Weight loss appears to be more difficult to achieve in women than men. This sex difference in weight loss could be related to women having less SNS and catecholamine response at a given intensity of exercise than men. Women may or may not have greater rates of lipolysis compared with men. ${ }^{[142]}$ 
Braun and Horton ${ }^{[18]}$ have speculated three possible mechanisms for the sex differences in lipolytic activity: (i) an interaction of SNS with estrogen, which increases the lipolytic actions; (ii) intramuscular stores of lipids may be more sensitive to SNS activity; and (iii) decreased carbohydrate metabolism, which causes more fat to be used simply by default. Additional research in this area is needed to determine the exact mechanism(s).

\section{Exercise-Induced Changes in Lipid Metabolism}

The influence of exercise on lipid metabolism is beyond the scope of this article but has been extensively studied and published in other articles. ${ }^{[19-24]}$ These review articles identify an inverse relationship between lipid metabolism during exercise and exercise intensity. Figure 3 is a summary of effects of exercise on lipid metabolism. Acute bouts of exercise appear to cause an increase the circulating levels of most hormones, while exercise training seems to lower (or have no effect) on resting hormonal concentrations. The increased hormones with acute exercise have the ability to enhance lipid oxidation and lipolysis, assuming adequate oxygen supply. Interestingly, the lower resting hormonal con-

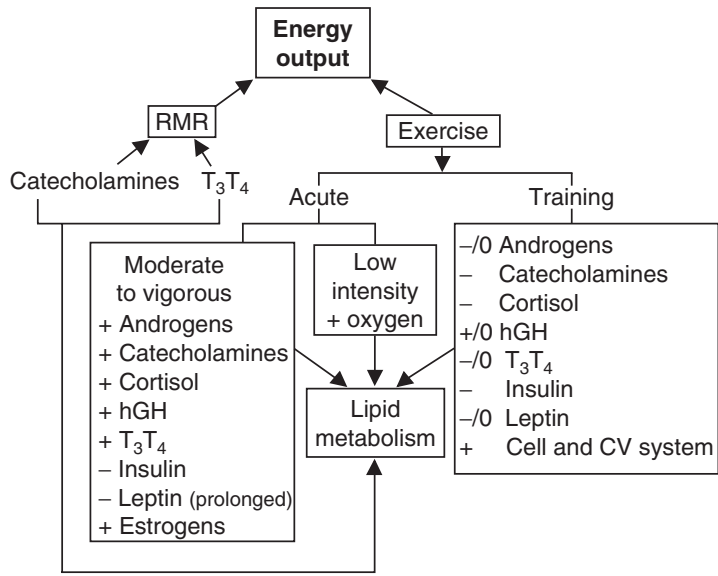

Fig. 3. Schematic representation of the metabolic hormonal that affects resting metabolic rate (RMR) and substrate use during exercise. $\mathbf{C V}=$ cardiovascular; $\mathbf{h G H}=$ human growth hormone; $\mathbf{T}_{3}=$ thyroxine; $\mathbf{T}_{4}=$ tri-iodothyronine; $\mathbf{0}$ indicates unchanged; - indicates decrease; + indicates increase. centrations associated with aerobic training also result in greater lipid utilisation.

Low-intensity exercise ( $<30 \%$ maximum oxygen consumption $\left.\left[\dot{\mathrm{V}}_{2 \mathrm{max}}\right]\right)$ uses predominantly lipids, which appears to be related to: (i) oxygen availability; (ii) the recruitment of slow twitch fibres that have extensive aerobic capabilities to metabolise lipid; and (iii) the capacity of the mitochondria to transport and metabolise fatty acids. ${ }^{[143]}$ In addition, lowintensity exercise relies mostly on adipose stores of lipid rather than intramuscular stores. ${ }^{[22]}$ Low-intensity exercise does not appear to cause significant changes in any of the major metabolic hormones, unless the activity becomes prolonged and causes a decline in plasma glucose concentrations. ${ }^{[17,22]}$

Moderate-intensity exercise $\left(40-65 \% \quad \dot{\mathrm{V}}_{2 \text { max }}\right)$ still uses significant amounts of fats for energy, but the source appears to be both adipose tissue and intramuscular stores. At this intensity, catecholamines increase, activating hormone-sensitive lipase. hGH increases, facilitating the effects of catecholamines on lipid metabolism. ${ }^{[23]}$ The SNS suppresses insulin and increases glucagon. In addition, the hypothalamus releases $\mathrm{CRH}$ causing the cascade of events that ultimately increases cortisol. These hormonal changes facilitate lipid metabolism until the rate of energy demand is greater than oxygen availability.

High-intensity exercise ( $\left.\geq 70 \% \dot{\mathrm{VO}}_{2 \max }\right)$ still uses small amounts of fats to produce energy, but glucose and glycogen are the predominant energy substrates. This reduced lipid metabolism could be related to increased lactate concentration, vasoconstriction in the adipose tissue, or inhibition of long-chain fatty acid uptake in the mitochondria. ${ }^{[23]}$ Interestingly, Yoshioka et al. ${ }^{[144]}$ have noted that fat oxidation after high-intensity exercise is greatly increased, possibly mediated by adrenergic mechanism. Finally, aerobic/endurance training allows for lipid metabolism to occur at a higher percentage of maximal capacity and is probably related to: (i) improved cellular capacity to metabolise lipids; (ii) improved oxygen availability; and (iii) an attenuated SNS/ catecholamine response to submaximal exercise. ${ }^{[145,146]}$ These physiological responses to exer- 
cise suggest that if dietary intake remains constant, then exercise should result in a loss of adipose stores.

\section{Exercise-Induced Changes in Adiposity}

Although a number of studies support exerciseinduced loss of fat stores without energy restriction, ${ }^{[147-149]}$ not all forms of exercise result in the same amount of loss. The majority of studies using low-intensity exercise programmes, such as walking, which should metabolise mostly fat, appear to result in little or no weight loss. ${ }^{[150-153]}$ However, Miyatake et al. ${ }^{[154]}$ using 31 obese Japanese men on ad lib diets, found that increased daily walking was directly associated with the decreased visceral adipose tissue. Moderate- to high-intensity endurance training, including running, cycling or aerobics, appears to cause loss of adiposity. ${ }^{[147,150,155-157]}$ Resistance, or strength, training may contribute to loss of fat stores, but it does not appear to have the same magnitude, or as significant an effect, as aerobic exercise. ${ }^{[158,159]}$ Other forms of exercise have not been extensively studied.

If one assumes that a typical exercise session lasts 30-60 minutes at a moderate intensity, then the total energy expenditure will range from 200 to 700 kcal (840-2900kJ). Since the intensity is usually moderate, then $40-60 \%$ of the energy will be derived from fat. Therefore, a typical exercise session will utilise between 9 and $47 \mathrm{~g}$ of fat, a relatively small amount of weight loss. However, if energy intake remains stable, this amount of exercise could have an impact on total adiposity over a prolonged period of time. Although, the loss of adiposity may be modest at best, the exercise will cause $\mathrm{T}_{3}$ levels to be maintained during the recovery from the exercise period, ${ }^{[160,161]}$ thus preserving resting metabolic rate; whereas diet-induced (i.e. energy restriction) weight loss causes a lowering of $\mathrm{T}_{3}$ and resting metabolic rate. Exercise also causes protein sparing, potentially via hGH, which will facilitate the maintenance of muscle mass. ${ }^{[162,163]}$ Preserving muscle mass helps sustain resting metabolic rate and therefore resting energy expenditure, which will help maintain equilibrium in the energy balance equation. Again, this effect is in opposition to the findings with diet-induced weight loss.

\section{Exercise-Induced Modifications of Hormones}

\subsection{Acute Exercise: Normal Weight Individuals}

A schematic of the effects of exercise on metabolic hormones and lipid metabolism is presented in figure 3 . The effects of acute exercise on metabolic hormones have been extensively reviewed in earlier work by us. ${ }^{[17]}$ In summary, the catecholamines appear to elevate in direct relation to increasing exercise intensity. ${ }^{[164,165]}$ Stallknecht et al. ${ }^{[166]}$ has suggested that the exercise-induced catecholamines release increases subcutaneous adipose tissue lipolysis. The mechanism appears to be an increased responsiveness of adipose tissue to $\beta$-adrenergic stimulation, as shown by a study using fat biopsies and isoprenaline, a $\beta$-adrenergic agonist. ${ }^{[167]}$ Cortisol may have a threshold for response such that exercise $<50 \%$ of $\dot{\mathrm{VO}}_{2 \text { max }}$ causes cortisol to decline, while exercise $>50 \%$ maximal capacity causes cortisol to increase. ${ }^{[168]}$ The increase in cortisol could be related to elevation of lactic acid in some way stimulating $\mathrm{ACTH},{ }^{[169]}$ increased IL- $6,{ }^{[13]}$ or it is possible that the increased SNS activity results in an elevation of NPY in the hypothalamus, resulting in an increase in $\mathrm{CRH}$, with a concomitant release of ACTH and cortisol. ${ }^{[170]}$

hGH is an important regulator of fat metabolism during exercise. ${ }^{[35,171]}$ hGH appears to have a response threshold, as Jenkins ${ }^{[172]}$ has shown that exercise intensity has to be $>30 \%$ of maximal capacity and for longer than 10 minutes to elicit a response. The mechanism appears to be a cholinergic pathway influencing the pituitary to secrete hGH or the hypothalamus to release GHRH. In addition, Farrell et al. ${ }^{[169]}$ have suggested that the increase may be due to lactic acid; however, this mechanism is equivocal. ${ }^{[164]}$ On the other hand, insulin declines with as little as 10 minutes of submaximal exercise, ${ }^{[173,174]}$ as long as the intensity is $>40 \%$ of $\dot{\mathrm{VO}}_{2 \text { max }}{ }^{[173]}$ The 
decline in insulin appears to be a direct influence of the SNS on pancreatic $\beta$ cells. ${ }^{[17]}$ Leptin does not appear to be influenced by low- or moderate-intensity exercise, ${ }^{[175,176]}$ unless the exercise is prolonged for several hours, such as a marathon, then leptin appears to decline. ${ }^{[177]}$ Some reports have suggested that the leptin response to exercise is delayed, peaking up to 48 hours post-exercise. ${ }^{[178,179]}$ The mechanism for such a delayed response is presently unknown. ${ }^{[180]}$ Interestingly, the studies supporting the delayed decrease in leptin used hour-long exercise sessions with a total energy expenditure of approximately $900 \mathrm{kcal}(3770 \mathrm{~kJ})$. One must keep in mind that most individuals would find it difficult to participate in an exercise session that would require that amount of energy. We are unaware of studies that have shown a similar effect of moderate-intensity exercise using shorter duration exercise.

The thyroid hormones do not appear to respond to acute bouts of submaximal or maximal exercise. ${ }^{[181-183]}$ In contrast, hypothalamic TSH appears to respond in proportion to exercise intensity or duration. ${ }^{[181]}$ However, preliminary studies from our laboratory have found decreases in TSH during recovery from acute exercise (personal observation). Since TSH has a delayed effect on the thyroid, an immediate post-exercise release of $\mathrm{T}_{3}$ or $\mathrm{T}_{4}$ from the thyroid would not be expected. Submaximal exercise appears to elevate both total and free testosterone as well as estradiol. ${ }^{[63,164,173,181]}$ Some of the change in the sex steroid hormones is related to haemoconcentration, ${ }^{[164,184]}$ but decreased hepatic clearance is also important. ${ }^{[17]}$ With prolonged exercise, testosterone appears to initially elevate, then decline. ${ }^{63,181]}$ The mechanism for the decline appears to be hypothalamic in origin, possibly involving opioids, prolactin, CRH, or gonadotrophic hormone-releasing hormone. ${ }^{[58]}$ In contrast to the androgens, we know little about the estrogen response to prolonged exercise; however, some studies have suggested that it increases. ${ }^{[65,165]}$

\subsection{Acute Exercise: Obese Individuals}

Although obese individuals appear to have a capacity for fat oxidation similar to normal weight individuals, ${ }^{[185,186]}$ obese individuals present different hormonal responses to exercise than normal weight individuals. The most significant changes are blunted SNS and catecholamine responses. ${ }^{[29]} \mathrm{Al}-$ though a blunted adrenergic response is evident, Hardman et al. ${ }^{[152]}$ has shown that prolonged exercise in obese men results in an increased responsiveness of adipose tissue to $\beta$-adrenergic stimulation of lipolysis. ${ }^{[167]}$ Thus, less stimulation could bring about lipolytic responses, similar to normal weight individuals. ${ }^{[187]}$ Obesity also appears to blunt the hGH response to moderate-intensity (60-70\% $\dot{\mathrm{V}}_{2 \max }$ ) exercise, ${ }^{[188,189]}$ but not the response to low-intensity exercise. ${ }^{[64]}$ The mechanism of the suppressed hGH activity may be related to the blunted SNS and catecholamine activity previously mentioned. ${ }^{[190,191]}$ Lower circulating hGH could diminish the normal impact of hGH on lipolysis and body fat. The insulin, leptin, $\mathrm{T}_{3}$ and testosterone responses to exercise do not appear altered in obese compared with normal weight individuals. ${ }^{[185,192]}$

\subsection{Training}

The influence of aerobic exercise training is somewhat different from the acute effects of aerobic exercise. Aerobic training results in lower resting levels of most metabolic hormones. ${ }^{[17]}$ For example, Winder et al. ${ }^{[174]}$ has shown that the catecholamine levels at rest and in response to exercise diminish with aerobic training. Similarly, insulin appears to decline with training, but insulin sensitivity increases. ${ }^{[174]}$ Resting cortisol levels may or may not be reduced by training, but the magnitude of the response of cortisol to submaximal exercise appears to decline with training, ${ }^{[77,193]}$ apparently as a result of altered ACTH functioning. ${ }^{[193,194]}$

Studies have reported that resting concentrations of leptin may decline with endurance or resistance training. ${ }^{[74,135,176,195-198]}$ However, this may not be the case for all individuals, as Kraemer et al. ${ }^{[199]}$ have shown that 9 weeks of training in obese women did not cause any significant change in either body fat or leptin; suggesting that extreme adiposity may alter the training response of leptin. In some studies, the response to exercise training has been associated 
with weight loss: ${ }^{[175,198]}$ however, other studies have concluded the effect to be independent of weight loss and more related to energy expenditure. ${ }^{[77,196-198]}$ Although resting levels of leptin may generally decline with training, Kraemer et al. ${ }^{[200]}$ using an intermittent, graded high-intensity exercise protocol in highly trained runners, did note transient increases in leptin after exercise, which abated quickly. This rapid response suggests that the changes were related to exercise-induced haemoconcentration, rather than leptin production. Studies have also suggested that trained subjects may have a delayed leptin response to exercise, apparently peaking 48 hours post-exercise. ${ }^{[178,179]}$ The mechanism for this response is presently unknown. The changes in resting leptin are not related to changes in catecholamines, but appear to be associated with changes in insulin. ${ }^{[197,201]}$ One study has raised the possibility that the response may be inversely coupled with hunger post-exercise not related to training per se. ${ }^{[202]}$

Resting hGH levels may not be influenced by training; ${ }^{[184,188]}$ however, it appears that the hGH response to exercise may be suppressed. ${ }^{[191]}$ Resting thyroid hormones do not appear to change with exercise training unless the training is extremely strenuous, ${ }^{[15]}$ but training may in turn, increase the sensitivity of cells to $\mathrm{T}_{3}{ }^{[160,161]}$ Resting total and free testosterone levels may be reduced with training, but not in all subjects. ${ }^{[138]}$ Kraemer et al. ${ }^{[200]}$ noted coinciding transient increases in testosterone and leptin after high-intensity exercise. Since all of their subjects exhibited an increase in testosterone but not leptin, the hormonal responses were not related. Other possible mechanisms for testosterone changes include alterations in the hypothalamus $(\mathrm{GnRH})$, pituitary (luteinising hormone or prolactin), or possibly hypothalamic disruption by cortisol. ${ }^{[138]}$ Thus, the training physiology of testosterone is not completely understood and is still in need of further investigation. Finally, training appears to decrease estrogens. ${ }^{[203,204]}$ The decrease may be related to lower circulating follicle-stimulating hormone and luteinising hormone, or chronic elevation of $\beta$-endorphin and cortisol. ${ }^{[17]}$ Severe training that disrupts energy balance can lead to menstrual function disruption; ${ }^{[66]}$ however, recreational exercise training may not disrupt reproductive functioning. ${ }^{[205,206]}$

Although we know that acute and chronic exercise cause perturbations in the hormones, we know little of the exact interactions between these hormones. Clearly, a relationship exists between the SNS, catecholamines and insulin during exercise. ${ }^{[17]}$ Similarly, relationships exist between catecholamines and cortisol, ${ }^{[164,181]}$ and catecholamine and hGH. ${ }^{[164]}$ However, these relationships appear to be more associative rather than causative. Since thyroid hormones, testosterone and estrogens may not consistently respond to acute or chronic exercise, we know little about the interrelationships between these and the other mentioned hormones during exercise. However, exercise does increase energy expenditure, with adipose tissue being a contributor to the sources of energy. Thus, if energy intake remains constant and energy expenditure is increased, lipid content of adipose tissue should ultimately decline. Therefore, in our view (figure 1), exercise would provide two signals influencing energy balance. First, it would directly influence the SNS and the HPA axis, which could directly influence energy intake. Secondly, exercise would affect the general hormonal milieu, which in turn, would influence energy balance. As to which of these signals has the greatest impact is currently unknown and is in need of resolution.

The reduction of these hormones with training seems to contrast the increased use of fats for energy during submaximal exercise reported in most exercise physiology texts and in detail by Coggan and Williams. ${ }^{[207]}$ Martin et al. ${ }^{[208]}$ and others ${ }^{[167,187]}$ have suggested that low levels of epinephrine and insulin, combined with normal $\mathrm{T}_{3}$ can work together to improve tissue lipolysis. An earlier study by Martin et al. ${ }^{[209]}$ using a detraining protocol in humans, has shown that training actually increases the response to catecholamines, potentially via increased $\beta$-adrenergic receptor sensitivity. With regard to insulin, low levels would permit lipolysis. In addition, data from a 6-week training study by Balsam and Lep- 
$\mathrm{po}^{[160]}$ suggest that the activity of the $\mathrm{T}_{3}$ is not reduced. Thus, these training-induced hormonal changes may have some supportive role in the extent of lipolysis.

The training-induced lipolytic activity is most significantly enhanced by adaptations that occur within the muscle and cardiovascular systems. ${ }^{[207]}$ Aerobic training increases blood flow and oxygen delivery to muscle, providing the key element for lipid metabolism. Within the muscle, there is increased mitochondria (size and content) and increased fatty acid transport proteins (e.g. carnitine palmitoyltransferase); thus, greater ability to use fats for energy. Training also decreases lactate formation at a given workload. Less lactate reduces its inhibitory effects on $\beta$-oxidation. Although fat oxidation increases, there is some question as to whether or not the source is from adipose tissue stores or intramuscular fat stores. ${ }^{[145]}$ If the source was intramuscular, then exercise training could have minimal impact on adipose tissue-derived lipolysis. This does not appear to be the case, at least for obese individuals, as Malenfant et al. ${ }^{[210]}$ have shown that 15 weeks of energy restriction and 21 weeks of training resulted in no change in intramuscular fat content, although there was considerable loss of fat mass. Since this was the first study on this topic and used a small sample size, there is a need for further verification of their results.

\section{Relationship Between Exercise-Induced Hormonal Changes and Body Fat}

The question remaining to be answered is what is the relationship between adiposity and exercise-induced hormonal changes? Clearly, adipose tissue is actively involved in energy production during exercise, providing both free fatty acids and glycerol for energy production. The effects of exercise on the hormone milieu during submaximal exercise potentiates the lipolytic effect, provided there is adequate blood flow and oxygen (figure 3). The SNS and the catecholamines appear to provide the underlying stimulus for lipid metabolism. The SNS and the catecholamines also act on insulin to lower its anti- lipidaemic effect and act to increase hypothalamic $\mathrm{CRH}$ and GHRH, resulting in increases in cortisol and hGH. These latter two hormones work synergistically to enhance lipolysis to a greater extent than either one would independently. ${ }^{[38]}$ Any feedback between cortisol and inhibition of hGH appears to be suppressed, ${ }^{[211]}$ potentially by the catecholamines; ${ }^{[190]}$ thus hGH increases. Also, cortisol appears to have only a small influence on lipid metabolism, but a major effect on gluconeogenesis. ${ }^{[26]}$ Since thyroid hormones, estrogens and testosterone may not respond substantially to acute exercise, the acute neuroendocrine responses to exercise regulating lipolysis appear to be related to catecholamines, insulin, hGH and cortisol.

Synergistically, all these hormones appear to maximise lipid metabolism more than expected from any one hormone acting individually. For example, studies have also shown that when exogenous hGH is administered to exercising individuals, no change in body composition occurs. This appears to be true with strength and power athletes, ${ }^{[39,212]}$ or with aerobically trained individuals. ${ }^{[34]}$ Marin et al. ${ }^{[47]}$ administered testosterone to 11 obese men for 8 months and found no changes in body mass index or waist circumference and only a very small change in total adiposity. It must be kept in mind that low levels of some hormones provide facilitative or permissive effects for other hormones and high concentrations of the hormone may negate this facilitative effect. $^{[17]}$

\section{Conclusions}

The study of metabolic hormonal interactions with adiposity is presently just beginning and much further work is needed to clarify these basic research findings so that we fully comprehend their implications and can ultimately use them in clinical situations. Our present state of knowledge suggests that a number of physiological and psychological systems that regulate energy intake and energy output work synergistically to maintain adipose tissue. However, adipose tissue is not passive in this process, as it secretes leptin, which has been linked to catecholamines, cortisol, insulin, hGH, thyroid hormones 
and the sex steroid hormones, all having some effect on lipid (and carbohydrate) metabolism. In addition, adipose tissue releases cytokines that can affect insulin, increase lipolysis and stimulate HPA to release cortisol. Thus, adipose tissue is acted upon by a number of physiological stimuli, including hormones, and at the same time, is an active component in the regulation of its own fat content via various hormonal feedback mechanisms.

All of the hormones mentioned above respond to exercise and have been in some way related to, or associated with each other. Thus, exercise is one of the major links between the hormonal modulators of energy intake and output. It appears that the key neuroendocrine components facilitating the lipolytic activity during exercise are the SNS and the catecholamines. These two stimuli have a direct effect on adipose metabolism and a direct effect on metabolic hormones, which influence adipose metabolism. Acute low- and moderate-intensity exercise results in hormonal changes that facilitate lipolytic activity. Exercise training appears to reduce these hormonal responses, but increases the sensitivity of these hormones so that lipolysis may be facilitated. Large amounts of adipose tissue appear to blunt the metabolic hormonal responses to exercise (circulating levels), but the sensitivity of these hormones to exercise seems to be increased, thus off-setting the lower levels and maintaining normal lipolytic activity. However, the influence of hormones on adipose tissue lipolysis during exercise may not be as significant as other physiological changes that occur with training, such as oxygen delivery and mitochondrial changes. Therefore, although the physiological role of the endocrine system during exercise and training is significant, other training effects appear to have as great, or greater, influence on lipolytic activity in adipose tissue.

\section{Acknowledgements}

The authors have provided no information on sources of funding or on conflicts of interest directly relevant to the content of this review.

\section{References}

1. Raymond CA. Biology, culture, dietary changes conspire to increase incidence of obesity. JAMA 1986; 256: 2157-8

2. French S, Castiglione K. Recent advances in the physiology of eating. Proc Nutr Soc 2002; 61: 489-96

3. Mohamed-Ali V, Pinkney JH, Coppack SW. Adipose tissue as an endocrine and paracrine organ. Int $\mathbf{J}$ Obes Relat Metab Disord 1998; 22: 1145-58

4. Pelleymounter MA, Cullen MJ, Baker MB, et al. Effects of the obese gene product on body weight regulation in ob/ob mice. Science 1995; 269: 540-3

5. Wang JL, Chinookoswong N, Yin S, et al. Calorigenic actions of leptin are additive to, but not dependent on, those of thyroid hormones. Am J Physiol Endocrinol Metab 2000; 279: E1278-85

6. McMurray RG, Harrell JS, Brown SA. Circulating leptin concentrations are not related to physical activity levels in adolescents. Clin Exerc Physiol 2000; 2: 139-44

7. Roberts SB, Nicholson M, Staten M, et al. Relationship between circulating leptin and energy expenditure in adults men and women aged 18 years to 81 years. Obes Res 1997; 5: 459-63

8. Pralong FP, Roduit R, Waeber G, et al. Leptin inhibits directly glucocorticoid secretion by normal human and rat adrenal gland. Endocrinology 1998; 139 (10): 4264-8

9. Sone M, Osamura RY. Leptin and the pituitary. Pituitary 2001; 4: $15-23$

10. Hotamisligil GS, Peraldi P, Budavari A, et al. IRS-1 mediated inhibition of insulin receptor tyrosine kinase activity in TNFalpha and obesity-induced insulin resistance. Science 1996; 271: $665-8$

11. Yamauchi T, Kamon J, Waki H, et al. The fat-derived hormone adiponectin reverses insulin resistance associated with both lipoatrophy and obesity. Nat Med 2001; 7: 941-6

12. Rothwell NJ. CNS regulation of thermogenesis. Crit Rev Neurobiol 1994; 8: 1-10

13. Steensberg A, Fisher CP, Keller C, et al. IL-6 enhances plasma IL-1ra, IL-10, and cortisol in humans. Am J Physiol Endocrinol Metab 2003; 285: E433-7

14. Berg M, Fraker DL, Alexander HR. Characterization of differentiation factor/leukemia inhibitory factor effect on lipoprotein lipase activity and mRNA in 3T3-L1 adipocytes. Cytokine 1994; 6: 425-32

15. Baylor LS, Hackney AC. Resting thyroid and leptin hormone changes in women following intense, prolonged exercise training. Eur J Appl Physiol 2003; 88: 480-4

16. Gomez-Merino D, Chennaoui M, Drogou C, et al. Decrease in serum leptin and prolonged physical activity. Med Sci Sports Exerc 2002; 34: 1594-9

17. McMurray RG, Hackney AC. Endocrine responses to exercise and training. In: Garrett WE, Kirkendall DT, editors. Exercise and sport science. Philadelphia (PA): Lippincott Williams \& Wilkins, 2002: 135-62

18. Braun B, Horton T. Endocrine regulation of exercise substrate utilization in women compared to men. Exerc Sport Sci Rev 2001; 29 (4): 149-54

19. Tremblay A, Després JP, Bouchard C. The effects of exercise training on energy balance and adipose tissue morphology and metabolism. Sports Med 1985; 2 (3): 223-33

20. Goldberg L, Elliott DL. The effect of exercise on lipid metabolism in men and women. Sports Med 1987; 4: 307-21

21. Brouns F, van der Vusse GJ. Utilization of lipids during exercise in human subjects: metabolic and dietary constraints. Br J Nutr 1998; 79: $117-28$ 
22. Jeukendrup AE, Saris WHM, Wagenmakers AJM. Fat metabolism during exercise: a review - part I: fatty acid mobilization and muscle metabolism. Int J Sports Med 1998; 19 (6): 231-44

23. Jeukendrup AE, Saris WHM, Wagenmakers AJM. Fat metabolism during exercise: a review - part II: regulation of metabolism and the effects of training. Int J Sports Med 1998; 19: 293-302

24. Jeukendrup AE, Saris WHM, Wagenmakers AJM. Fat metabolism during exercise: a review - part III: effects of nutritional interventions. Int J Sports Med 1998; 19: 371-9

25. Steinacker JM, Lormes W, Reissnecker S, et al. New Aspects of the hormone and cytokine response to training. Eur J Appl Physiol 2004 Apr; 91 (4): 382-91

26. Bjorntrop P, Rosmond R. Obesity and cortisol. Nutrition 2000; 16: $924-36$

27. Fliers E, Kreier F, Voshol PJ, et al. White adipose tissue: getting nervous. J Neuroendocrinol 2003; 15 (11): 1005-10

28. Astrup A. The sympathetic nervous system as a target for intervention in obesity. Int J Obes Relat Metab Disord 1995; 19 Suppl. 7: S24-8

29. Arner P. Catecholamine-induced lipolysis in obesity. Int J Obes Relat Metab Disord 1999; 23 Suppl. 1: 10-3

30. Poirier P, Eckel RH. Adipose tissue metabolism and obesity. In: Bouchard C, editor. Physical activity and obesity. Champaign (IL): Human Kinetics, 2000: 181-200

31. Pucci E, Chiovato L, Pinchera A. Thyroid and lipid metabolism. Int J Obes Relat Metab Disord 2000; 24 Suppl. 2: S109-12

32. Yamaki M, Murayama N, Yoshida K, et al. Subcellular distribution of thyroxine monodeiodinasae activity in rabbit kidney. Horm Metab Res 1991; 23 (1): 7-11

33. Kunesova M, Hainer V, Obenberger J, et al. Adipose tissue distribution in obese females: relationship to androgens, cortisol, growth hormones and leptin. Sb Lek 2002; 103: 477-85

34. Drent ML, Wever LDV, Ader HJ, et al. Growth hormone administration in addition to a very low calorie diet and exercise program in obese subjects. Eur J Endocrinol 1995; 132 (5): 565-72

35. Davidson MB. Effects of growth hormone on carbohydrate and lipid metabolism. Endocr Rev 1987; 8 (2): 115-31

36. Hales CN, Luzio JP, Siddle K. Hormonal control of adipose tissue lipolysis. Biochem Soc Symp 1978; 43: 97-135

37. Jensen MB, Kissmeyer-Nielsen P, Laurberg S. Perioperative growth hormone treatment increases nitrogen and fluid balance and results in short-term and long-term conservation of lean tissue mass. Am J Clin Nutr 1998; 68 (4): 840-6

38. Djurhuus $\mathrm{CB}$, Gravholt $\mathrm{CH}$, Nielsen $\mathrm{S}$, et al. Additive effects of cortisol and growth hormone on regional and systemic lipolysis in humans. Am J Physiol Endocrinol Metab 2004; 286 (3): E488-94

39. Deyssig R, Frisch H, Blum WF, et al. Effect of growth hormone treatment on hormonal parameters, body composition and strength in athletes. Acta Endocrinol (Copenh) 1993; 128 (4): 313-8

40. Musey VC, Goldstein S, Farmer PK, et al. Differential regulation of IGF-1 and IGF-binding protein-1 by dietary composition in humans. Am J Med Sci 1993; 305 (3): 131-8

41. Bertoli A, DePirro R, Fusco A, et al. Differences in insulin receptors between men and menstruating women and influence of sex hormones on insulin binding during the menstrual cycle. J Clin Endocrinol Metab 1980; 50 (2): 246-50

42. Mandour T, Kissebah AH, Wynn V. Mechanism of oestrogen and progesterone effects on lipid and carbohydrate metabo- lism: alteration in the insulin: glucagon molar ratio and hepatic enzyme activity. Eur J Clin Invest 1977; 7: 181-7

43. Ruby BC, Robergs RA, Waters DL, et al. Effects of estradiol on substrate turnover during exercise in amenorrheic females. Med Sci Sports Exerc 1997; 29 (9): 1160-9

44. Shamoon H, Felig P. Effects of estrogen on glucose uptake by rat muscle. Yale J Biol Med 1974; 47 (4): 227-33

45. Xu X, DePergola G, Bjorntrop P. The effects of androgens on the regulation of lypolysis and the number of $\beta$-adrenoceptors in male rat adipocytes. Endocrinology 1991; 128: 379-82

46. Bhasin S. Effects of testosterone administration on fat distribution, insulin sensitivity and atherosclerosis progression. Clin Infect Dis 2003; 37 Suppl. 2: S142-9

47. Marin P, Holmang S, Jonsson L, et al. The effect of testosterone treatment on body composition and metabolism in middleaged obese men. Int J Obes Relat Metab Disord 1992; 16: 991-7

48. Longcope C, Baker R, Johnston CC. Androgen and estrogen metabolism: relationship to obesity. Metabolism 1986; 35 (3): 235-7

49. Seidell JC, Bjorntrop P, Sjostrom L, et al. Visceral fat accumulation in men is positively associated with insulin, glucose and C-peptide levels, but negatively associated with testosterone levels. Metabolism 1990; 39: 897-901

50. Chihara K, Kodama H, Kaji H, et al. Augmentation by propranolol of growth hormone-releasing hormone (1-4)NH2-induced growth hormone release in short and normal children. J Clin Endocrinol Metab 1985; 61 (2): 229-33

51. Troisi RJ, Weiss ST, Parker DR, et al. Relation of obesity and diet to sympathetic nervous system activity. Hypertension 1991; 17 (5): 669-77

52. Dinan TG, Thakore J, O'Keane V. Lowering cortisol enhances growth hormone response to growth hormone releasing hormone in healthy subjects. Acta Physiol Scand 1994; 151 (3): 413-6

53. Giustina A, Bresciani E, Bossoni S, et al. Recriprocol relationship between the level of circulating cortisol and growth hormone secretion in response to growth hormone-releasing hormone in man: studies in patients with adrenal insufficiency. J Clin Endocrinol Metab 1994; 79 (5): 1266-72

54. Samra JS, Clark ML, Humphreys SM, et al. Is the growth hormone concentration regulated by the morning rise in the plasma cortisol concentration? Horm Metab Res 1996; 28 (5): 237-40

55. Rosmond R, Chagnon YC, Holm G, et al. A glucocorticoid receptor gene marker is associated with abdominal obesity, leptin and dysregulation of the hypothalamic-pituitary-adrenal axis. Obes Res 2000; 8 (3): 211-8

56. Hermida RC, Garcia L, Ayala DE, et al. Circadian variation of plasma cortisol in prepubertal children with normal stature, short stature and growth hormone deficiency. Clin Endocrinol (Oxf) 1999; 50: 473-9

57. Ghizzoni L, Mastorakos G, Street ME, et al. Leptin, cortisol and HG secretion interactions in short normal prepubertal children. J Clin Endocrinol Metab 2001; 86 (8): 3729-34

58. Hackney AC. Testosterone, the hypothalamo-pituitary-testicular axis, and endurance exercise training: a review. Biol Sport 1996; 13: 85-98

59. Ding JH, Sheckter CB, Drinkwater BL, et al. High serum cortisol in exercise-associated amenorrhea. Ann Intern Med 1988; 108: 530-4

60. Pedersen SB, Borglum JD, Brixen K, et al. Relationship between sex hormones, body composition and metabolic risk 
parameters in permenopausal women. Eur J Endocrinol 1995; 133 (2): 200-6

61. Ivandic A, Prpic-Krizevac I, Sucic M, et al. Hyperinsulinemia and sex hormones in healthy premenopausal women: relative contribution of obesity, obese type, and duration of obesity. Metabolism 1998; 47: 13-9

62. Ovesen P, Moller J, Lunde JO, et al. Effect of growth hormone administration on circulating levels of luteinizing hormone, follicle stimulating hormone and testosterone in normal healthy men. Hum Reprod 1993; 8: 1869-72

63. Hackney AC, Ness RJ. Hormonal profiles and nitrogen balance during intensive aerobic-anaerobic training: effects of a dietary protein supplement. Acta Kinanthropol 1996; 32: 31-41

64. Hansen A, Weeke J. Fasting serum growth hormone levels and growth hormone response to exercise during normal menstrual cycles and cycles of oral contraceptives. Scand J Clin Lab Invest 1974; 34 (3): 199-205

65. Kanaley JA, Boileau RA, Bahr JA, et al. Substrate oxidation and $\mathrm{GH}$ responses to exercise are independent of menstrual phase status. Med Sci Sports Exerc 1992; 24: 873-80

66. Loucks AB, Verdun M, Heath EM. Low energy availability, not stress of exercise, alters LH pulsitility in exercising women. J Appl Physiol 1998; 84: 37-46

67. Paolisso G, Rizzo MR, Mone CM, et al. Plasma sex hormones are significantly associated with plasma leptin concentration in health subjects. Clin Endocrinol (Oxf) 1998; 48: 291-7

68. Ahima RS, Dushay J, Flier SN, et al. Leptin accelerates the onset of puberty in normal female mice. J Clin Invest 1997; 99: 391-5

69. Giustina A, Wehrenberg WB. Influence of thyroid hormones on the regulation of growth hormone secretion. Eur J Endocrinol 1995; 133 (6): 646-53

70. Harvey S. Thyrotropin-releasing hormone: a growth hormone releasing factor. J Endocrinol 1990; 125 (3): 345-58

71. Nussey SS, Whitehead SA. Endocrinology: an integrated approach. Oxford: BIOS Scientific Publishers Ltd, 2001

72. Wolthers T, Grofte T, Moller N, et al. Calorigenic effects of growth hormone: the role of thyroid hormones. J Clin Endocrinol Metab 1996; 81 (4): 1416-9

73. Coiro V, Volpi R, Capretti L, et al. Influence of thyroid status on the paradoxical growth hormone response to thyrotropin-releasing hormone in human obesity. Metabolism 1994; 43: 514-7

74. Ahima RS, Prabakaran D, Mantzoros C, et al. Role of leptin in neuroendocrine responses to fasting. Nature 1996; 382: 25-32

75. Hansen KR, Krasnow SM, Nolan MA, et al. Activation of the sympathetic nervous system by galan-like peptide: a possible link between leptin and metabolism. Endocrinology 2003; 144: 4709-17

76. Rayner DV, Trayhurn P. Regulation of leptin production: sympathetic nervous system interactions. J Mol Med 2001; 79 (1): 8-20

77. Simsch C, Lormes W, Petersen KG, et al. Training intensity influences leptin and thyroid hormones in highly trained rowers. Int J Sports Med 2002; 23 (6): 422-7

78. Florkowski CM, Collier GR, Zimmet PZ, et al. Low-dose growth hormone replacement lowers plasma leptin and fat stores without affecting body mass index in adults with growth hormone deficiency. Clin Endorcinol (Oxf) 1996; 45: 769-73

79. Tuominen JA, Laquier FW, Heiman ML, et al. Leptin, exercise, and energy balance. Diabetes 1996; 45 Suppl. 2: 256A
80. Diekman MJ, Romijn JA, Endert E, et al. Thyroid hormones modulate serum leptin levels: observations in thyrotoxic and hypothyroid women. Thyroid 1998; 8: 1081-6

81. Mantzoros CS, Ozata M, Negrao A, et al. Synchronicity of frequently sampled thyrotropin and leptin concentrations in healthy adults and leptin-deficient subjects: evidence for possible partial regulation by leptin in humans. J Clin Endocrinol Metab 2001; 86 (7): 3284-91

82. Sesmilo G, Casamitjana R, Halperin I, et al. Role of thyroid hormones on serum leptin levels. Eur J Endocrinol 1998; 139: 428-30

83. Fekete C, Kelly J, Mihaly J, et al. Neuropeptide Y has a central inhibitory action on the hypothalamic -pituitary-thyroid axis. Endocrinology 2001; 142 (6): 2606-13

84. Alagna S, Cossu ML, Masala A, et al. Evaluation of serum leptin levels and thyroid function in morbidly obese patients treated with baratric surgery. Eat Weight Disord 2003; 8 (2): 95-9

85. Wabitsch M, Jensen PB, Blum WF, et al. Insulin and cortisol promotes leptin expression in human fat cells. Diabetes 1996; 45: $1435-8$

86. Richard D, Rivest R, Naimi N, et al. Expression of corticotropin-releasing factor and its receptors in the brain of lean and obese Zucker rats. Endocrinology 1996; 137: 4786-95

87. Elimam A, Knutsson U, Bronnegard M, et al. Variations in glucocorticoid levels within the physiological range affect plasma leptin levels. Eur J Endocrinol 1998; 139: 615-20

88. Haffner SM, Miettinen H, Karhappaa P. Leptin concentrations, gender hormones, and cortisol in non-diabetic men. J Clin Endocrinol Metab 1997; 82 (6): 1807-9

89. Bornstein RS, Uhlmann K, Haidan A, et al. Evidence for a novel peripheral action of leptin as a metabolic signal to the adrenal gland: leptin inhibits cortisol release directly. Diabetes 1997; 46: $1235-8$

90. Lasson H, Ahern B. Short-term dexamethasone treatment increases plasma leptin independently of changes in insulin sensitivity in healthy women. J Clin Endocrinol Metab 1996; 86: 4428-32

91. Licinio J, Mantzoros C, Negrao AB, et al. Human leptin levels are pulsitile and inversely related to pituitary-adrenal function. Nat Med 1997; 3 (5): 575-9

92. Askari H, Liu J, Dagogo-Jack S. Hormonal regulation of human leptin in vivo: effects of hydrocortisone and insulin. Int J Obes Relat Metab Disord 2000; 24: 1254-9

93. De Pergola G. The adipose tissue metabolism: role of testosterone and dehydroepiandosterone. Int J Obes Relat Metab Disord 2000; 24 Suppl. 2: S59-63

94. Dagogo-Jack S, Fanelli C, Paramore D, et al. Plasma leptin and insulin relationships in obese and nonobese humans. Diabetes 1996; 45: 695-8

95. Tanizawa $\mathrm{Y}$, Okuya S, Ishihara H, et al. Direct stimulation of basal insulin secretion by physiological concentrations of leptin and pancreatic $\beta$ cells. Endocrinology 1997; 138: 4513-6

96. Mueller W, Gregoire FM, Stanhope KL, et al. Evidence that glucose metabolism regulates leptin secretion from cultured rat adipocytes. Endocrinology 1998; 139: 551-8

97. Wang J, Liu R, Hawkins M, et al. A nutrient sensing pathway regulates leptin gene expression in muscle and fat. Nature 1998; 393: 684-8

98. Orban Z, Bornstein SR, Chrousos GP. The interaction between leptin and the hypothalamic-pituitary-thyroid axis. Horm Metab Res 1998; 30 (5): 231-5 
99. Flier JS, Harris M, Hollenberg AN. Leptin, nutrition, and the thyroid: the why, the wherefore, and the wiring. J Clin Invest 2000; 105: 859-61

100. Roemmich JN, Rogol AD. Hormonal changes during puberty and their relationship to fat distribution. Am J Hum Biol 1999; 11 (2): 209-24

101. McMurray RG, Proctor CR, Wilson WL. Effect of caloric deficit and dietary manipulation on aerobic and anaerobic exercise performance. Int J Sports Med 1991; 12 (2): 167-72

102. Smith AT, Clemmons DR, Underwood LE, et al. Effect of exercise on plasma somatomedin-C/insulin-growth factor I concentrations. Metabolism 1987; 36: 533-7

103. Jones PP, Davy KP, Alexander S, et al. Age-related increase in muscle sympathetic nerve activity is associated with abdominal adiposity. Am J Physiol 1997; 272: E976-80

104. Seals DR, Bell C. Chronic sympathetic activation: consequence and cause of age- associated obesity. Diabetes 2004; 53: 276-85

105. Del Rio G. Adrenomedullary function and its regulation in obesity. Int J Obes Relat Metab Disord 2000; 24 Suppl. 2: S89-91

106. Hansen BC, Jen KL, Pek SB, et al. Rapid oscillations on plasma insulin, glucagons, and glucose in obese and normal weight humans. J Clin Endocrinol Metab 1982; 54 (4): 785-92

107. Monroe MB, Van Pelt RE, Schiller BC, et al. Relation of leptin and insulin to adiposity-associated elevations in sympathetic activity with age in humans. Int J Obes Relat Metab Disord 2000; 24 (9): 1183-7

108. Pasquali R, Vicennati V. Activity of the hypothalamic-pituitaryadrenal axis in different obese phenotypes. Int J Obes Relat Metab Disord 2000; 24 Suppl. 2: S47-9

109. Phillips GB, Jing T, Heymsfeild SB. Relationship in men of sex hormones, insulin, adiposity and risk factors for myocardial infarction. Metabolism 2003; 52: 784-90

110. Ukkola O, Gagnon J, Rankinen T, et al. Age, body mass index, race and other determinants of steroid hormone variability: the heritage family study. Eur J Endocrinol 2001; 145 (1): 1-9

111. Jockenhovel F, Blum WF, Vogel E, et al. Testosterone substitution normalizes elevated serum leptin levels in hypogonadal men. J Clin Endocrinol Metab 1997; 82 (8): 2510-3

112. Zang YW, Stern B, Rebar RW. Endocrine comparison of obese menstruating and amenorrheic women. J Clin Endocrinol Metab 1984; 58: 1077-83

113. Bouchard C, Tremblay A, Despres JP, et al. The response to long-term overfeeding in identical twins. N Eng J Med 1990; 322 (21): 1477-82

114. Bjorntorp P, Rosmond R. Neuroendocrine abnormalities in visceral obesity. Int J Obes Relat Metab Disord 2000; 24 Suppl. 2: S80-5

115. Frayn KN, Karpe F, Fielding BA, et al. Integrative physiology of human adipose tissue. Int J Obes Relat Metab Disord 2003; 27 (8): 875-88

116. Esler M, Rumantir M, Wiesner G, et al. Sympathetic nervous system and insulin resistance: from obesity to diabetes. Am J Hypertens 2001; 14: 304S-9S

117. Unger RH. Lipotoxic diseases. Ann Rev Med 2002; 53: 319-36

118. Matsuki T, Horai R, Sudo K, et al. IL-1 plays an important role in lipid metabolism by regulating insulin levels under physiological conditions. J Exp Med 2003; 198: 877-88

119. Boulton KL, Hudson DU, Coppack SW, et al. Steroid hormone interconversion in human adipose tissue in vivo. Metabolism 1992; 41: 556-9
120. Marsoobian V, Grosvenor M, Jacob M, et al. Very-low-energy diets alter the counterregulatory response to falling plasma glucose concentrations. Am J Clin Nutr 1995; 61 (2): 373-8

121. Oppert JM, Nadeau A, Tremblay A, et al. Negative energy balance with exercise in identical twins: plasma glucose and insulin responses. Am J Physiol 1997; 272: E248-54

122. Weinstock RS, Dai H, Wadden TA. Diet and exercise in the treatment of obesity: effects of 3 interventions on insulin resistance. Arch Intern Med 1998; 158: 2477-83

123. Chan JM, Rimm EB, Colditz GA, et al. Obesity, fat distribution, and weight gain as risk factors for clinical diabetes in men. Diabetes Care 1994; 17: 961-9

124. Colditz GA, Willett WC, Rotnitzky A, et al. Weight gain as a risk factor for clinical diabetes mellitus in women. Ann Intern Med 1995; 122: 481-6

125. Wing RR, Venditti E, Kakioio JM, et al. Lifestyle intervention in overweight individuals with family history of diabetes. Diabetes Care 1998; 21: 350-9

126. Nindl BC, Friedl KE, Frykman PN, et al. Physical performance and metabolic recovery among lean, healthy men following a prolonged energy deficit. Int J Sports Med 1997; 18 (5): $317-24$

127. McCargar LJ, Crawford SM. Metabolic and anthropometric changes with weight cycling in wrestlers. Med Sci Sports Exerc 1992; 24 (11): 1270-5

128. Eggena P, Sowers JR, Maxwell MH, et al. Hormonal correlates of weight loss associated with blood pressure reduction. Clin Exp Hypertens 1991; 13 (8): 1447-56

129. Sowers JR, Whitfield LA, Catania RA, et al. Role of the sympathetic nervous system in blood pressure maintenance in obesity. J Clin Endocrinol Metab 1982; 54 (6): 1181-6

130. Reseland JE, Anderssen SA, Solvoll K, et al. Effect of long-term changes in diet and exercise on plasma leptin concentrations. Am J Clin Nutr 2001; 73 (2): 240-5

131. Rosenbaum M, Nicolson M, Hirsch J, et al. Effects of weight change on plasma leptin concentrations and energy expenditure. J Clin Endocrinol Metab 1997; 82 (11): 3647-54

132. Wadden TA, Considine RV, Foster GD, et al. Short- and longterm changes in serum leptin in dieting obese women: effects of caloric restriction and weight loss. J Clin Endocrinol Metab 1998; 83 (1): 214-8

133. Postel-Vinay MC, Saab C, Gourmelen M. Nutritional status and growth hormone-binding protein. Horm Res 1995; 44: 177-81

134. Vance ML, Hartman ML, Thorner MO. Growth hormone and nutrition. Horm Res 1992; 38 Suppl. 1: 85-8

135. Kraemer WJ, Volek JS, Clark KL, et al. Influence of exercise training on physiological and performance changes with weight loss in men. Med Sci Sports Exerc 1999; 31 (9): 1320-9

136. Turcato E, Zamboni M, DePergola G, et al. Interrelationship between weight loss, body fat distribution and sex hormones in pre- and postmenopausal obese women. J Intern Med 1997; 241: 363-72

137. Yanovski JA, Yanovski SZ, Gold PW, et al. Differences in corticotrophin-releasing hormone-stimulated adrenocorticotropin and cortisol before and after weight loss. J Clin Endocrinol Metab 1997; 82: 1874-8

138. Hackney AC, Dobridge J. Exercise and male hypogonadism: testosterone, the HPT axis and physical exercise. In: Winters SJ, editor. Male hypogonadism: basic, clinical, and therapeutic principles. Totowa (NJ): Human Press, 2004: 305-29

139. Strauss RH, Lanese RR, Malarkey WB. Weight loss in amateur wrestlers and its effect on serum testosterone levels. JAMA $1985 ; 254: 3337-8$ 
140. Olson BR, Cartledge T, Sebring N, et al. Short-term fasting affects luteinizing hormone secretory dynamics but not reproductive function in normal-weight sedentary women. J Clin Endocrinol Metab 1995; 80 (4): 1187-93

141. DeSouza MJ, Metzger DA. Reproductive dysfunction in amenorrheic athletes and anorexic patients: a review. Med Sci Sports Exerc 1991; 23 (9): 995-1007

142. Mittendorfer B, Horowitz JF, Klein S. Effect of gender on lipid kinetics during endurance exercise of moderate intensity in untrained subjects. Am J Physiol Endocrinol Metab 2002; 283 (1): E58-65

143. Winder WW, Arogyasami J, Barton RJ, et al. Muscle malonylCoA decreases during exercise. J Appl Physiol 1989; 67: 2230-3

144. Yoshioka M, Doucet E, St-Pierre S, et al. Impact of highintensity exercise on energy expenditure, lipid oxidation and body fatness. Int J Obes Relat Metab Disord 2001; 25 (3): 332-9

145. Hurley BF, Nemeth PM, Martin WH, et al. Muscle triglyceride utilization during exercise: effect of training. J Appl Physiol 1986; 60: 562-7

146. Rahkila P, Soimajärvi J, Karvinen E, et al. Lipid metabolism during exercise II: respiratory exchange ration and muscle glycogen content during $4 \mathrm{~h}$ bicycle ergometry and two groups of healthy men. Eur J Appl Physiol Occup Physiol 1980; 44 (3): $246-54$

147. Tremblay A, Simoneau J-A, Bouchard C. Impact of exercise intensity on body fatness and skeletal muscle metabolism. Metabolism 1994; 43: 814-8

148. Wilmore JH. Body composition in sport and exercise: directions for future research. Med Sci Sports Exerc 1983; 15 (1): 21-31

149. Wilmore JH. Variations in physical activity habits and body composition. Int J Obes Relat Metab Disord 1995; 19 Suppl. 4: S107-12

150. Bryner RW, Toffle RC, Ullrich IH, et al. The effect of exercise intensity on body composition, weight loss and dietary composition in women. J Am Coll Nutr 1997; 16 (1): 68-73

151. Cauley JA, Kriska AM, LePorte RE, et al. A two-year randomized exercise trial in older women: effects on HDL-cholesterol. Atherosclerosis 1987; 66: 247-58

152. Hardman AE, Jones PRM, Norgan NG, et al. Brisk walking improves endurance fitness without changing body fatness in previously sedentary women. Eur J Appl Physiol Occup Physiol 1992; 65: 354-9

153. Santiago M, Leon AS, Serfass RC. Failure of 40 weeks of brisk walking to alter blood lipids in normolipemic women. Can J Appl Physiol 1995; 20: 417-28

154. Miyatake N, Nishikawa H, Morishita A, et al. Daily walking reduces visceral adipose tissue areas and improves insulin resistance in Japanese obese subjects. Diabetes Res Clin Pract 2002; 58 (2): 101-7

155. DiPietro L, Williamson DF, Casperson CJ, et al. The descriptive epidemiology of selected physical activities and body weight among adults trying to lose weight: the behavioral risk factor surveillance system survey, 1989. Int J Obes Relat Metab Disord 1993; 17: 69-76

156. Harrell JS, Johnston LF, Griggs TR, et al. An occupational based physical activity intervention program: improving fitness and decreasing obesity. AAOHN J 1996; 44 (8): 377-84

157. Thomas EL, Brynes AE, McCarthy J, et al. Preferential loss of visceral fat following aerobic exercise, measured by magnetic resonance imaging. Lipids 2000; 35: 769-76
158. Ballor DL, Keesey RE. A meta-analysis if the factors affecting exercise-induced changes in body mass, fat mass and fat free mass in males and females. Int J Obes Relat Metab Disord 1991; 15: 717-26

159. Marks BL, Rippe JM. The importance of fat free mass maintenance in weight loss programmes. Sports Med 1996; 22: 273-81

160. Balsam A, Leppo LE. Effect of physical training on the metabolism of thyroid hormones in man. J Appl Physiol 1975; 38: $212-5$

161. Rone JK, Dons RF, Reed HL. The effect of endurance training on serum triiodothyronine kinetics in man: physical conditioning marked by enhanced thyroid hormone metabolism. Clin Endocrinol (Oxf) 1992; 37: 325-30

162. Mehls O, Tönshoff B, Kovacs $\mathrm{G}$, et al. Interaction between glucocorticoids and growth hormone. Acta Pediatr Suppl 1993; 388: 77-82

163. Yeh JK, Aloia JF, Chen M, et al. Effect of growth hormone administration and treadmill exercise on body composition of rats. J Appl Physiol 1994; 77: 23-9

164. Kindermann W, Schnabel A, Schmitt WM, et al. Catecholamines, growth hormone, cortisol, insulin and sex hormones in aerobic and anaerobic exercise. Eur J Appl Physiol 1982; 49: 389-99

165. McMurray RG, Forsythe WA, Mar MH, et al. Exercise intensity-related responses of B-endorphin and catecholamines. Med Sci Sports Exerc 1987; 19: 570-4

166. Stallknecht B, Lorentsen J, Enevoldsen LH, et al. Role of sympathoadrenergic system in adipose tissue metabolism during exercise in humans. J Physiol 2001; 536 (pt 1): 283-94

167. Harant I, Marion-Latard F, Crampes F, et al. Effect of a longduration physical exercise on fat cell lipolytic responsiveness to adrenergic agents and insulin in obese men. Int J Obes Relat Metab Disord 2002; 26 (10): 1373-8

168. Davies CTM, Few JD. Effects of exercise on adrenocortical function. J Appl Physiol 1973; 35: 887-91

169. Farrell PA, Garthwaite TL, Gustafson AB. Plasma adrenocorticotropin and cortisol responses to submaximal and exhaustive exercise. J Appl Physiol 1983; 55: 1441-4

170. Bove AA. Hormonal responses to acute and chronic exercise. Int Union Physiol Sci 1989; 4: 143-6

171. Gibney J, Healy ML, Stolinski M, et al. Effects of growth hormone $(\mathrm{GH})$ on glycerol and free fatty acid metabolism during exhaustive exercise in GH-deficient adults. J Clin Endocrinol Metab 2003; 88: 1792-7

172. Jenkins PJ. Growth hormone and exercise. Clin Endocrinol (Oxf) 1999; 50: 683-9

173. Viru A. Plasma hormones and physical exercise. Int J Sports Med 1992; 13: 201-9

174. Winder WW, Hickson RC, Hagberg JM, et al. Training-induced changes in hormonal and metabolic responses to submaximal exercise. J Appl Physiol 1979; 46: 766-71

175. Perusse L, Collier G, Gagnon J, et al. Acute and chronic effects of exercise on leptin levels in humans. J Appl Physiol 1997; 83: $5-10$

176. Racette SB, Coppack SW, Landt M, et al. Leptin production during moderate-intensity aerobic exercise. J Clin Endocrinol Metab 1997; 82: 2275-7

177. Leal-Cerro A, Garcia-Luna PP, Astorga R, et al. Serum leptin levels in male marathon athletes before and after the marathon run. J Clin Endocrinol Metab 1998; 83: 2376-9 
178. Essig DA, Alderson NL, Ferguson MA, et al. Delayed effects of exercise on plasma leptin concentration. Metabolism 2000; 49: 395-9

179. Olive JL, Miller GD. Differential effects of maximal- and moderate-intensity runs on plasma leptin in healthy trained subjects. Nutrition 2001; 17 (5): 365-9

180. Torjman MC. On the delayed effects of exercise on leptin: more questions than answers. Nutrition 2001; 17: 420-2

181. Galbo H, Hummer L, Petersen IB, et al. Thyroid and testicular hormone responses to grade and prolonged exercise in man. Eur J Appl Physiol 1977; 36: 101-6

182. Schmid P, Wolf W, Pilger E, et al. TSH, T3, rT3 and fT4 in maximal and submaximal physical exercise. Eur J Appl Physiol 1982; 48: 31-9

183. Siddiqui AR, Hinnefeld RB, Dillon T, et al. Immediate effects of heavy exercise on the circulating thyroid hormones. Br J Sports Med 1983; 17: 180-3

184. McMurray RG, Eubank TK, Hackney AC. Nocturnal hormonal responses to resistance exercise. Eur J Appl Physiol 1996; 72: 121-6

185. Marion-Latard F, Crampes F, Zakaroff-Girard A, et al. Postexercise increase of lipid oxidation after a moderate exercise bout in untrained healthy obese men. Horm Metab Res 2003; 35: $97-103$

186. Schrauwen P, Van Marken Lichtenbelt WD, Saris WH, et al. Fat balance in obese subjects: role of glycogen stores. Am J Physiol Endocrinol Metab 1998; 274: E1027-33

187. Borsheim E, Lonnroth P, Knardahl S, et al. No difference in lipolytic response to beta- adrenoceptor stimulation in situ but a delayed increase in adipose tissue blood flow in moderate obese compared with lean men in the postexercise period. Metabolism 2000; 49: 579-87

188. Kanaley JA, Weatherup-Dentes MM, Jaynes EB, et al. Obesity attenuates the growth hormone response to exercise. J Clin Endocrinol Metab 1999; 84: 3156-61

189. Weltman A, Weltman JY, Veldhuis JD, et al. Body composition, physical exercise, growth hormone and obesity. Eat Weight Disord 2001; 6 Suppl. 3: 28-37

190. Bertherat J, Bluet-Pajot MT, Epelbaum J. Neuroendocrine regulation of growth hormone. Eur J Endocrinol 1995; 132: 12-24

191. Weltman A, Weltman JY, Womack C, et al. Exercise training decreases the growth hormone $(\mathrm{GH})$ response to acute constant-load exercise. Med Sci Sports Exerc 1997; 29: 669-76

192. Henriksen EJ. Effects of acute exercise and exercise training on insulin resistance. J Appl Physiol 2002; 93: 788-96

193. Duclos M, Corcuff JB, Rashedi M, et al. Trained versus untrained men: different immediate post-exercise responses of pituitary adrenal axis: a preliminary study. Eur J Appl Physiol 1997; 75: 343-50

194. Buono MJ, Yeager JE, Sucec AA. Effects of aerobic training on the plasma ACTH response to exercise. J Appl Physiol 1987; 63: 2499-501

195. Franks PW, Farooqi IS, Luan J, et al. Does physical activity energy expenditure explain the between-individual variation in plasma leptin concentrations after adjusting for differences in body composition? J Clin Endocrinol Metab 2003; 88: 3258-63

196. Hickner RC, Racette SB, Binder EF, et al. Effects of 10 days of endurance exercise training on the suppression of whole body and regional lipolysis by insulin. J Clin Endocrinol 2000; 85: 1498-504
197. Pasman WJ, Westertrep-Plantenga MS, Saris WHM. The effect of exercise training on leptin levels in obese males. Am J Physiol Endocrinol Metab 1998; 37: E280-6

198. Thong FS, Hudson R, Ross R, et al. Plasma leptin in moderate obese men: independent effects of weight loss and aerobic exercise. Am J Physiol Endocrinol Metab 2000; 279: E307-13

199. Kraemer RR, Kraemer GR, Acevedo EO, et al. Effects of aerobic exercise on serum leptin levels in obese women. Eur J Appl Physiol 1999; 80: 154-8

200. Kraemer RR, Durand RJ, Acevedo EO, et al. Effects of highintensity exercise on leptin and testosterone concentrations in well-trained males. Endocrinology 2003; 21: 261-5

201. Ryan AS, Partley RE, Elahi D, et al. Changes in leptin and insulin action with resistive training in postmenopausal women. Int J Obes Relat Metab Disord 2000; 24: 27-32

202. Tsofliou F, Pitsiladis YP, Malkova D, et al. Moderate physical activity permits acute coupling between serum leptin and appetite-satiety measures in obese women. Int $\mathrm{J}$ Obes Relat Metab Disord 2003; 27: 1332-9

203. Bullen BA, Skrinar GS, Beitins IZ, et al. Endurance training effects on plasma hormonal responsiveness and sex hormone excretion. J Appl Physiol 1984; 56: 1453-63

204. Bonen A, Belcastro AN, Ling WY, et al. Profiles of selected hormones during menstrual cycles of teenage athletes. J Appl Physiol 1981; 50: 545-51

205. Bonen A. Recreational exercise does not impair menstrual cycles: a prospective study. Int J Sports Med 1992; 13: 110-20

206. Harber VJ. Menstrual dysfunction in athletes: an energetic challenge. Exerc Sport Sci Rev 2000; 28 (1): 19-23

207. Coggan AR, Williams BD. Metabolic adaptations to endurance training: substrate metabolism during exercise. In: Hargreaves M, editor. Exercise metabolism. Champaign (IL): Human Kinetics Publishers Inc., 1995: 177-210

208. Martin WH, Dalsky GP, Hurley BF, et al. Effects of exercise training on plasma free fatty acid turnover and oxidation during exercise. Am J Physiol Endocrinol Metab 1993; 75: E708-14

209. Martin WH, Coyle EF, Joyner M, et al. Effects of stopping exercise training on epinephrine-stimulated lipolysis in humans. J Appl Physiol 1984; 56: 845-8

210. Malenfant P, Tremblay A, Doucet E, et al. Elevated intramyocellular lipid concentration in obese subjects is not reduced after diet and exercise training. Am J Physiol Endocrinol Metab 2001; 280: E632-9

211. Bluet-Pajot MT, Epelbaum J, Gourdji D, et al. Hypothalamic and hypophyseal regulation of growth hormone secretion. Cell Mol Neurobiol 1998; 18: 101-23

212. Yarasheski KE, Campbell JA, Smith K, et al. Effect of growth hormone and resistance raining on muscle growth in young men. Am J Physiol Endorcinol Metab 1992; 262 (3 pt 1): E261-7

Correspondence and offprints: Prof. Robert G. McMurray, CB\#8700, Fetzer Gym, University of North Carolina, Chapel Hill, NC 27599-8700, USA.

E-mail: exphys@email.unc.edu 